\title{
Use of Pesticides on Crops and Its Impact on Health
}

\author{
Cyril Kanmony J* \\ Scott Christian College, Nagercoil, India
}

* Corresponding author: Cyril Kanmony J, Scott Christian College, Nagercoil, India.

Received Date: February 03, 2020

Published Date: February 11, 2020

\section{Opinion}

Pesticides refer to agro-chemicals that are used for protecting plants from pests. Pesticides are classified into insecticides, fungicides, herbicides and others including plant-growth-regulators. Liberal use of agro-chemicals results in the presence of excess pesticide residues in the edible parts of plants and food grains. It is proved by many laboratory-based studies [1]. The indiscriminately sprayed pesticides and insecticides also results in the pollution of air, water and soil. Pollution reduces our life span by increasing our exposure to environment-related health hazards [2,3]. Further due to overuse of these poisonous pesticides and insecticides, these pests and insects become immune to these chemicals and become more dangerous than before. We use these poisonous chemicals to kill the damage-causing pests without knowing their impact on human health. They have the potential to kill not only pests and insects but also various beings including human beings. Why do then we use these poisonous agro-chemicals?

Pests, weeds and diseases destroy crops to the extent of $40 \%$ in developing countries. The net impact is a decline in the yield and output. In India, it is estimated at 35\% to 45\% [4]. Hence it is utmost necessity to control these damage-causing pests and insects to enhance production. But nobody bothers about the residues present in edible parts of plants and food grains that humans consume. A recent report published by All India Network Project on Pesticide Residues finds that residues of pesticides were found in $18.75 \%$ of samples tested. These samples include vegetables, cereals, pulses, egg, fish, meat, spices, tea, milk, and surface water. In some samples residues of multiple pesticides have been detected. Even mild doses also result in serious adverse health effects by getting accumulated in our body over a period. The most dangerous matter is that the diseases caused by these pesticides cannot be cured.
In European and other developed countries, all chemicals and bacteria are within the prescribed limit. But in India, there is no monitoring system to regulate the usage of these pesticides and insecticides and Indian farmers are uneducated and so they buy and use many pesticides without consulting field experts. They use them even in the absence of disease symptoms. It results in overusing of these agro-chemicals and consequently the presence of excess amount of pesticide residues in food items. They also use these pesticides carelessly without following the required protective measures as they don't know the hazardous effects of pesticides. The production and consumption of these agro-chemicals, in India, is continuously increasing due to the patronage of governments though these agro-chemicals and chemical fertilizers were introduced in India only after Green Revolution to increase food production. Hence, the total food production in India increased from 82 million tonnes in 1960-1961 to 176 million tonnes in 1990-1991. The production of grains has reached an all-time high of 281 million tonnes in 2018-2019,

Even the usage of poisonous and hazardous pesticides and insecticides is not regulated. In India, as on 30.08.2016, 275 pesticides were registered for use. Of these 255 are chemical poisons and 115 are highly hazardous (Kumar and Narasimha 2017). In the supply of agro-chemicals, India stood at the 4th place after the US, Japan and China. India's pesticides industry is the biggest in Asia and $12^{\text {th }}$ in the world. The Ministry of Chemicals and Fertilisers (GOI 2019a) [5] reports show that the production of key pesticides increased from 186,490 MTs in 2014-2015 to 216,703 MTs in 2018-2019. The consumption also increased from 56,121 MTs in 2014-2015 to 62,183 MTs in 2017-2018. But the consumption of these chemicals was only 39,773 MTs in 2005-2006. Of the total 
pesticides consumed, nearly $70 \%$ is consumed by five States, namely: Uttar Pradesh, Maharashtra, Andhra Pradesh, Punjab and Haryana. Crop wise data show that more than $18 \%$ of pesticides are used on paddy, the most staple food of Indians and 50\% on cotton. On an average, the consumption of pesticides in India is $0.29 \mathrm{~kg} /$ ha. But it is as high as $0.74 \mathrm{~kg}$ in Punjab, $0.62 \mathrm{~kg}$ in Haryana and $0.57 \mathrm{~kg}$ in Maharashtra and as low as $0.03 \mathrm{~kg}$ in Madhya Pradesh (GOI 2019) [6].

The presence of traces of dangerous pesticides that we use as pest-control chemicals creates many health problems. The most dangerous fact is that the diseases caused by these pesticides cannot be cured. The health problems range from short-term illnesses like headache and nausea to chronic impacts like cancer, reproductive harm and endocrine disruption. Long-term exposure to pesticides also leads to Parkinson's diseases, asthma, depression and anxiety and attention deficit hyperactivity disorder (ADHD). Children in comparison with adults breathe more air, eat more food and drink more water per unit of body weight and so among all the most vulnerable are children. A recent report points out that since 2005 there has been a general increase of 11\% in ADHD, while there has been a $175 \%$ increase in cases among children between 3 and 17 years of age. The final consequence of the presence these pesticides in human body is death. It is reported that in developing countries nearly 800,000 people have died due to pesticides since the onset of Green Revolution and every year the death toll due to pesticide consumption through their food is about 2,000. There is also a continuous increase in the disease burden of human beings. Increase in ill-health results in increase in health-related expenditure [7].

It is our duty to keep the environment clear and the world intact for the future generation. The question here arises is: can our crops survive without using or at least without overusing these pesticides and insecticides? The simple answer for the question is: 'yes', andour crops can survive without these agro-chemicals. There are different methods to control these pests and insects. Some measures are sustainable and eco-friendly. The best method to stop the use pesticides is organic farming, in which most of the damage-causing pests and insects can be kept away from farms without creating any damage to the environment. For example, in Tamil Nadu, India, Nam Alwar, a perfect organic farmer, solved many problems of farmers without using any pesticide.

\section{Acknowledgement}

None.

\section{Conflict of interest}

No conflict of interest.

\section{References}

1. Khullar, Bhavya, Rajeshwari Sinha, Amit Khurana (2019) Too much too often, Indiscriminate use of antibiotics on food crops in several parts of the country could be making them ineffective on humans. Down To Earth, pp: 16-19.

2. Kanmony J Cyril (2010) Drinking Water Management: Problems and Prospects, Mittal Publications, New Delhi, India.

3. Koshy Jacob (2016a) "Fine Particulates Causing Chronic Illness", The Hindu, p: 11.

4. Devi P Indira, Judy Thomas, Rajesh K Rajan (2017) Pesticides Consumption in India: A Spatiotemporal Analysis. Agricultural Economics Research Review 30 (1): 163-172.

5. Government of India (2019) Production of Key Chemicals During 20142015 to 2018-2019, Ministry of Chemicals and Fertilizers, Department of Chemicals and Petro-chemicals (online).

6. Government of India (2019) States/UTs Zonal Conference on Inputs of Plant Protection during Karif and Rabi Seasons (online).

7. Kanmony J Cyril (2013) Health Care in Rural Areas, Mittal Publications, New Delhi, India. 